\title{
OBTENÇÃO DE PECTINASES EM CULTIVO SUBMERSO DE Aspergillus oryzae SOB DIFERENTES CONDIÇÕES DE pH
}

\author{
L. MENEGHEL, C. ROSSI, G. PELLENZ REIS, C. REGINATTO, \\ E. MALVESSI, M. M. SILVEIRA \\ Universidade de Caxias do Sul, Instituto de Biotecnologia \\ E-mail para contato: 1mscatharina@ucs.br
}

\begin{abstract}
RESUMO - A produção de pectinases por Aspergillus oryzae é fortemente influenciada pelo meio e pelos parâmetros de processo. $\mathrm{O}$ pH atua sobre a composição do complexo, a atividade e a estabilidade de pectinases durante o cultivo. Neste trabalho, avaliou-se o crescimento celular de A. oryzae e a produção de pectinases em cultivos conduzidos sob cinco diferentes condições de controle de pH. Obteve-se maior concentração de biomassa em pH 4,0 constante; porém, nesta condição, a atividade enzimática foi praticamente nula. Verificou-se que a atividade pectinolítica $(24 \mathrm{U} / \mathrm{mL})$ é preservada quando o $\mathrm{pH}$ é ajustado inicialmente em 4,0 e, após queda natural, mantido em mínimo de 2,7 até o final do cultivo. A mais alta atividade enzimática $(43 \mathrm{U} / \mathrm{mL})$ foi obtida em cultivo no qual o $\mathrm{pH}$ foi mantido constante em 4,0 até $24 \mathrm{~h}$ e, em seguida, reduzido para 2,7 pela adição de $\mathrm{HCl}$. Os resultados confirmam que o $\mathrm{pH}$ afeta decisivamente $\mathrm{o}$ cultivo de $A$. oryzae e a sua capacidade de produção de pectinases.
\end{abstract}

\section{INTRODUÇÃO}

As enzimas pectinolíticas, ou pectinases, possuem aplicações em diferentes setores comerciais, em especial na indústria de alimentos, nas etapas de extração e clarificação de sucos de frutas e vinhos (Reid e Ricard, 2000; Hoondal et al., 2002; Gummadi e Panda, 2003; Busto et al., 2006; Olivier et al., 2008; Sandri et al., 2011; Sandri et al., 2013). Estas enzimas degradam as substâncias pécticas que conferem alta viscosidade a polpas e sucos de frutas, facilitando, assim, as etapas de filtração e concentração, aumentando o rendimento global do processo. Uma característica que favorece a aplicação de pectinases fúngicas na indústria de alimentos é o fato de o $\mathrm{pH}$ ideal de ação de suas enzimas se aproximar do valor de $\mathrm{pH}$ de muitos sucos de frutas, ou seja, na faixa de 3,0 a 5,5 (Ueda et al., 1982).

As pectinases podem ser produzidas por muitas espécies de fungos filamentosos, algumas leveduras e bactérias (Kashyap et al., 2001). As preparações enzimáticas comerciais, no entanto, são geralmente produzidas com fungos filamentosos, especialmente os do gênero Aspergillus. Na produção de pectinases por A. oryzae em processo submerso, o pH exerce efeito direto sobre os resultados do processo de produção de pectinases. Segundo Ueda et al. (1982), o pH influencia tanto a produção quanto a composição do complexo pectinolítico sintetizado por A. oryzae. Fawole e Odunfa (2003) e Patil e Dayanand (2006) identificaram que a produção de enzimas pécticas por fungos do gênero Aspergillus ocorre em faixa ácida de pH. Malvessi e Silveira (2004) verificaram que o crescimento de A. oryzae é favorecido em 


\section{9 a 22 de outubro de 2014 \\ Florianópolis/SC}

valores de $\mathrm{pH}$ em torno de 4,0 e que a síntese de poligalacturonases, hidrolases do grupo das pectinases, é aumentada com pH em torno de 3,0. Segundo Fontana et al. (2009), também em estudos sobre o cultivo de $A$. oryzae, quando o $\mathrm{pH}$ foi controlado em mínimo de 2,7 , houve um aumento significativo na produção de poligalacturonases, enquanto que, abaixo deste valor, o metabolismo do microrganismos e a produção das enzimas foram prejudicados.

Desta forma, este trabalho teve o objetivo de avaliar o crescimento celular de $A$. oryzae e a produção de pectinases em cultivos submersos conduzidos sob cinco diferentes condições de controle de $\mathrm{pH}$.

\section{MATERIAIS E MÉTODOS}

O microrganismo utilizado foi $A$. oryzae IPT-301, cedido pelo Instituto de Pesquisas Tecnológicas de São Paulo. O meio de cultivo empregado foi o descrito por Meneghel (2013), composto de extrato de farelo de trigo, glicose, pectina, extrato de levedura e sais. Os cultivos foram conduzidos em biorreator de bancada (Tecnal, modelo Tecbio), com 4,0L de meio, frequência de agitadores e fluxo de ar de $480 \mathrm{rpm}$ e $0,42 \mathrm{vvm}$, a $28^{\circ} \mathrm{C}$, por $160 \mathrm{~h}$. O indutor enzimático - pectina cítrica - foi adicionado ao meio somente após $24 \mathrm{~h}$ de cultivo e o $\mathrm{pH}$ foi controlado nos valores desejados com $\mathrm{NaOH} 2,5 \mathrm{M}$ e $\mathrm{HCl} 2,0 \mathrm{M}$.

Os cultivos foram realizados em duplicata, sob cinco diferentes condições, durante os seguintes ensaios, com adição de pectina em $24 \mathrm{~h}$ de processo:

- $\mathrm{T} 1-\mathrm{pH}$ mantido constante em 4,0;

- $\mathrm{T} 2$ - pH mantido constante em 2,7;

- T3 - pH inicial de 4,0 e, após a queda natural, controlado em mínimo de 2,7;

- T4 - pH inicial 4,0 e, após a queda natural, mantido em 2,7 até o final do cultivo;

- T5 - pH inicial 4,0 mantido constante até $24 \mathrm{~h}$, em seguida reduzido para 2,7, pela adição de $\mathrm{HCl}$, e controlado até o final do cultivo.

O crescimento celular foi avaliado por gravimetria e os açúcares redutores totais (ART), pelo método descrito por Bitmann (1974), que prevê a hidrólise ácida, adaptado para amostras isentas de sólidos em suspensão. O método para determinação de ART não sofre a influência da pectina.

A atividade de pectinases totais foi avaliada pelo método descrito por Malvessi (2000). Este método é baseado na medida da redução da viscosidade de uma solução padrão de pectina a $0,63 \%(\mathrm{~m} / \mathrm{v})$ submetida à ação de enzimas pectinolíticas que rompem as ligações glicosídicas internas da cadeia de ácido poligalacturônico.

A velocidade específica de crescimento celular $\left(\mu_{\mathrm{X}}\right)$ foi determinada a partir das concentrações celulares medidas nas amostras, durante a fase exponencial do cultivo.

$\mathrm{O}$ fator de produção específica $\left(\mathrm{Y}_{\mathrm{P} / \mathrm{X}}\right)$ foi calculado a partir dos máximos valores de atividade enzimática $\left(\mathrm{P}_{\max }\right)$ e concentração de biomassa $\left(\mathrm{X}_{\max }\right)$ obtidos no cultivo.

Os fatores de conversão de substrato em produto $\left(\mathrm{Y}_{\mathrm{P} / \mathrm{S}}\right)$ e em células $\left(\mathrm{Y}_{\mathrm{X} / \mathrm{S}}\right)$ foram calculados a partir dos máximos valores de atividade enzimática $\left(\mathrm{P}_{\max }\right)$ e concentração de 
biomassa $\left(\mathrm{X}_{\max }\right)$ obtidos no cultivo, e da concentração de substrato consumido até o tempo em que ocorreram os picos.

\section{RESULTADOS E DISCUSSÃO}

O estudo do efeito do pH sobre o cultivo de $A$. oryzae IPT-301 foi conduzido com base em ensaios prévios (dados não mostrados), em que 4,0 foi o valor inicial que proporcionou maior obtenção de biomassa, assim como nos estudos de Malvessi \& Silveira (2004) e Fontana \& Silveira (2012).

A pectina cítrica, indutor enzimático de pectinases, foi adicionada ao cultivo após a fase de intenso crescimento celular, na tentativa de facilitar o fornecimento de oxigênio para o microrganismo durante este período. Além disso, a alta viscosidade conferida ao meio do cultivo pela pectina dificulta o controle dos parâmetros de processo, podendo influenciar o estudo do $\mathrm{pH}$.

Os resultados gerais dos cultivos, para todas as condições de $\mathrm{pH}$ avaliadas são resumidos na Tabela 1. O crescimento celular e a produção de pectinases foram favorecidos no Ensaio T5. Já os fatores de produção específica ( $\left.\mathrm{Y}_{\mathrm{P} / \mathrm{X}}\right)$ obtidos nos ensaios T2, T3, T4 e T5 foram similares. Estes resultados indicam que, nesta condição, maiores concentrações de biomassa resultaram em altas atividades de pectinases. A condição avaliada no Ensaio T1 ( $\mathrm{pH}$ 4,0 constante) se mostrou favorável ao crescimento celular no entanto, ensaios anteriores demonstraram que os títulos enzimáticos obtidos foram praticamente nulos.

Tabela 1 - Resultados gerais de cultivo de Aspergillus oryzae em biorreator de bancada, sob diferentes condições de $\mathrm{pH}$

\begin{tabular}{l|ccccc}
\hline & T1 & T2 & T3 & T4 & T5 \\
\hline $\mathbf{X}_{\max }(\mathbf{g} / \mathbf{L})$ & 4,6 & 3,3 & 3,8 & 3,6 & 6,3 \\
$\mathbf{t}_{\mathbf{X}, \max }(\mathbf{h})$ & 28 & 27 & 24 & 24 & 36 \\
$\boldsymbol{\mu}_{\mathbf{X}, \mathbf{m a x}}\left(\mathbf{h}^{-\mathbf{1}}\right)$ & 0,16 & 0,15 & 0,16 & 0,16 & 0,18 \\
$\mathbf{t}_{\mathbf{\mu X}, \mathbf{m a x}}(\mathbf{h})$ & 13 & 15 & 17 & 17 & 19 \\
$\mathbf{S}_{\mathbf{c o n s}}(\mathbf{g} / \mathbf{L})$ & 11,8 & 10,0 & 10,8 & 10,2 & 10,8 \\
$\mathbf{P}_{\max }(\mathbf{U} / \mathbf{m L})$ & n.d. & 20 & 24 & 24 & 43 \\
$\mathbf{t}_{\mathbf{P}, \mathbf{m a x}}(\mathbf{h})$ & n.d. & 153 & 115 & 72 & 140 \\
$\mathbf{Y}_{\mathbf{P} / \mathbf{X}}(\mathbf{U} / \mathbf{m g})$ & n.d. & 6,06 & 6,32 & 6,67 & 6,82 \\
$\mathbf{Y}_{\mathbf{X} / \mathbf{S}}(\mathbf{g} / \mathbf{g})$ & 0,39 & 0,33 & 0,35 & 0,35 & 0,58 \\
$\mathbf{Y}_{\mathbf{P} / \mathbf{S}}(\mathbf{U} / \mathbf{m g})$ & n.d. & 2,00 & 2,22 & 2,35 & 3,98 \\
$\left.\mathbf{p}_{\mathbf{V}} \mathbf{( U / m L} / \mathbf{h}\right)$ & n.d. & 0,13 & 0,21 & 0,33 & 0,31 \\
$\mathbf{p H}_{\text {min }}$ & 4,0 & 2,7 & 2,7 & 2,7 & 2,7 \\
$\mathbf{p H}_{\text {final }}$ & 4,0 & 2,7 & 7,2 & 2,7 & 2,7 \\
\hline
\end{tabular}

$\mathrm{X}_{\max }$ - máxima concentração de biomassa; $\mathrm{t}_{\mathrm{X}, \max }-$ tempo em que ocorreu $\mathrm{X}_{\max } ; \mu_{\mathrm{X}, \max }-$ máxima velocidade específica de crescimento celular; $\mathrm{t}_{\mu \mathrm{X}, \max }$ - tempo em que ocorreu $\mu_{\mathrm{X}, \max } ; \mathrm{S}_{\mathrm{cons}}-$ consumo total de ART; $\mathrm{P}_{\max }$ - máxima atividade de pectinases; $t_{\mathrm{P}, \max }$ - tempo em que ocorreu $\mathrm{P}_{\max } ; \mathrm{Y}_{\mathrm{P} / \mathrm{X}}$ - fator de produção específica; $\mathrm{Y}_{\mathrm{X} / \mathrm{S}}$ - fator de conversão de substrato em células; $\mathrm{Y}_{\mathrm{P} / \mathrm{S}}$ - fator de conversão de substrato em pectinases; $\mathrm{p}_{\mathrm{V}}$ - produtividade volumétrica; $\mathrm{pH}_{\min }-$ mínimo valor de $\mathrm{pH}$ do cultivo; $\mathrm{pH}_{\text {final }}$ - valor final de $\mathrm{pH}$ do cultivo. n.d. - não determinado. 
Na Figura 1, são ilustrados os perfis de crescimento celular e as velocidades específicas em função do tempo nos ensaios T1 a T3. Esta análise inicial foi feita considerando-se as 33 primeiras horas de cultivo, visto que, após este período, o crescimento microbiano nestes ensaios já se encontrava em fase estacionária. Ressalte-se que os Ensaios T4 e T5, no período 0 a 33h, tiveram condições operacionais idênticas às de T3 e T1, respectivamente.

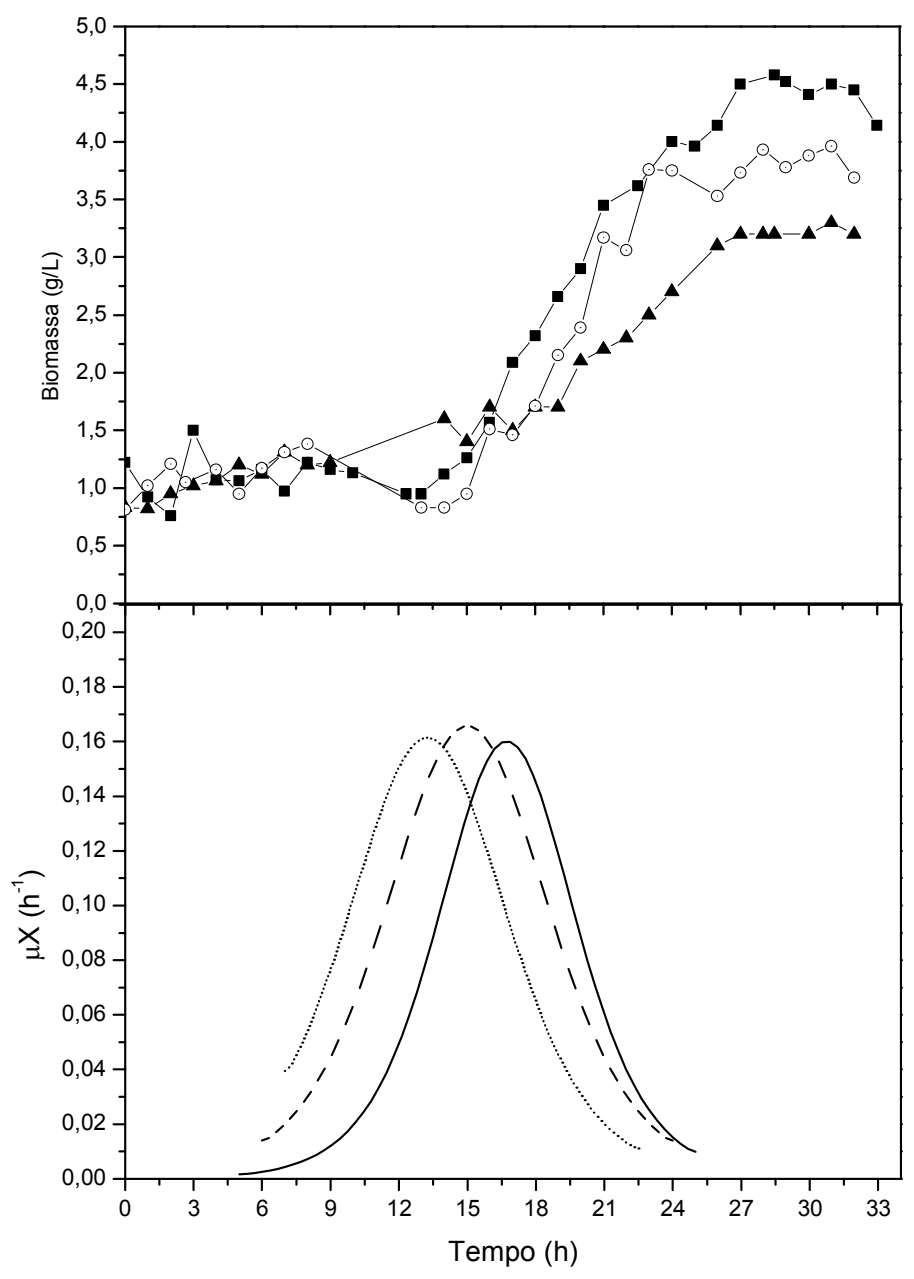

Figura 1 - Variação da concentração de biomassa e da velocidade específica de crescimento obtidos em cultivo de Aspergillus oryzae em biorreator de bancada em diferentes condições de $\mathrm{pH}:(\boldsymbol{\square}, \ldots) \mathrm{T} 1: \mathrm{pH}$ mantido constante em 4,0; $(\boldsymbol{\Delta},-) \mathrm{T} 2: \mathrm{pH}$ mantido constante em 2,7; $(\circ,---)$ T3: pH inicial 4,0 e, após queda, controlado em mínimo de 2,7.

Verificou-se que o controle do $\mathrm{pH}$ em 4,0 (Ensaio T1) favoreceu o crescimento celular, proporcionando a obtenção de maiores títulos de biomassa em relação às demais condições testadas. Os perfis de velocidade específica de crescimento $\left(\mu_{\mathrm{X}}\right)$ apresentaram comportamento similar, com valores de $\mu_{\mathrm{X}, \max }$ muito próximos; porém, estes picos foram alcançados em tempos diferentes de processo para cada condição, sugerindo que a adaptação do microrganismo a cada condição de $\mathrm{pH}$ ocorre de forma diferente. No Ensaio T1, o valor de $\mu_{\mathrm{X}, \max }$ foi atingido em menor tempo de cultivo (13h), em razão do favorecimento do 
crescimento celular neste $\mathrm{pH}$. Por outro lado, no Ensaio T2, em pH 2,7 constante, o pico de $\mu_{\mathrm{X}}$ ocorreu mais tarde, alcançando-se menor concentração de biomassa.

Verifica-se que o $\mathrm{pH}$ afeta diretamente o crescimento celular de $A$. oryzae, sendo que no ensaio mantido em pH 2,7 constante, T2, foi o que apresentou menor concentração final de biomassa.

$\mathrm{O}$ estudo do efeito do $\mathrm{pH}$ sobre a produção e a atividade de pectinases obtidas em cultivo de $A$. oryzae foi realizado utilizando as condições apresentadas para os ensaios T1 a T5. Os perfis de $\mathrm{pH}$ e atividade de pectinases para os cultivos estão apresentados na Figura 2. Nestes ensaios, avaliou-se o cultivo até $160 \mathrm{~h}$.

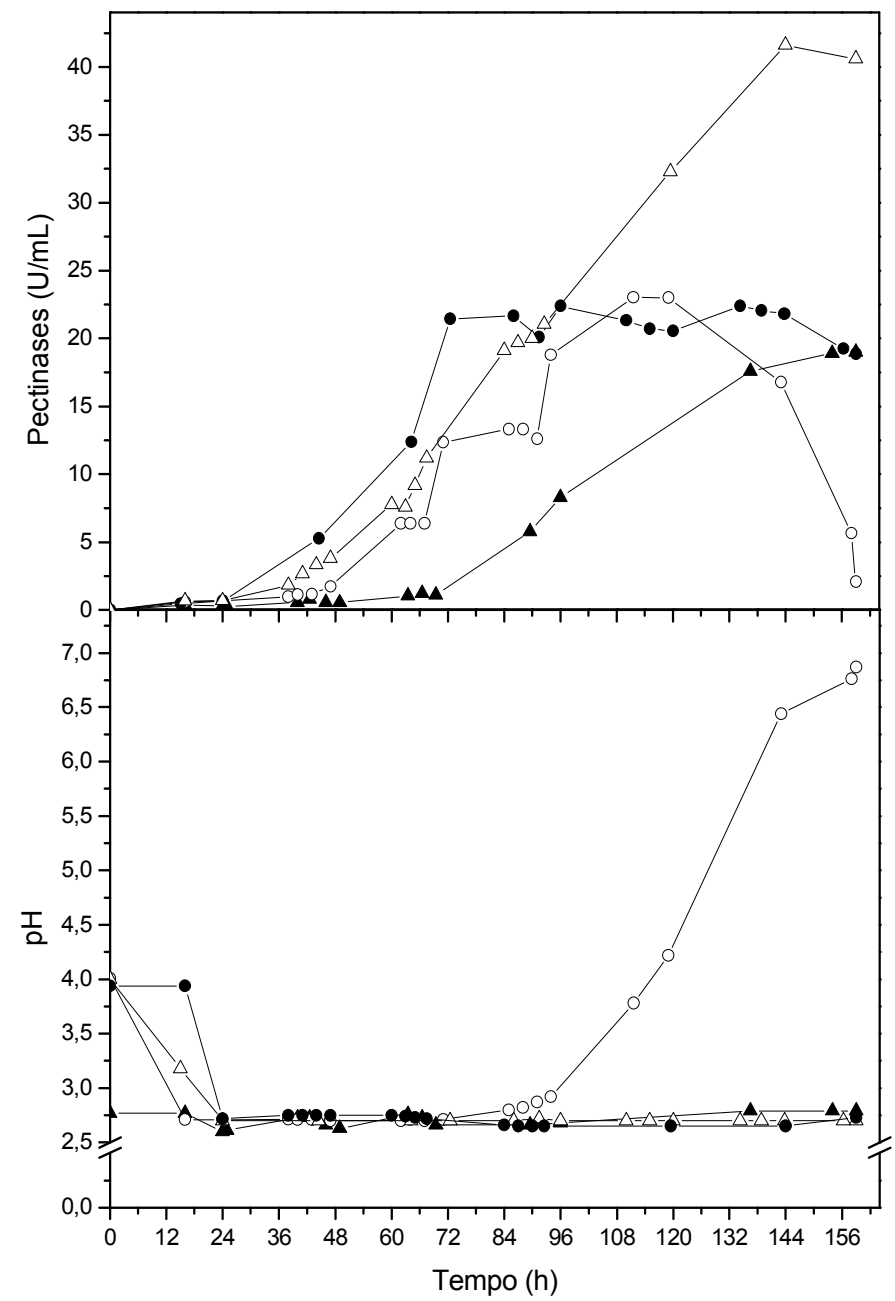

Figura 2 - Variação da atividade de pectinases e do $\mathrm{pH}$ em cultivo de Aspergillus oryzae em biorreator de bancada, sob diferentes condições de $\mathrm{pH}$ : ( $\boldsymbol{\Delta}$ ) T2 $-\mathrm{pH}$ mantido constante em 2,7; (०) T3 - pH inicial 4,0 e, após queda, controlado em mínimo de 2,7, (•) T4 - pH inicial 4,0 e, após queda, mantido constante em 2,7, até o final do cultivo; $(\Delta) \mathrm{T} 5-\mathrm{pH}$ inicial 4,0 mantido constante até 24 horas, em seguida reduzido para 2,7 pela adição de $\mathrm{HCl}$ e controlado até o final do cultivo. 
Conforme discutido anteriormente, a condição de pH do Ensaio T1 (pH 4,0 constante), apesar de favorecer o crescimento celular, não permitiu a obtenção de atividade enzimática em ensaios anteriores; portanto, não será considerada nesta análise. Contudo, o Ensaio T2 ( $\mathrm{pH}$ 2,7 constante), apesar de proporcionar baixos valores de concentração de biomassa em relação às demais condições testadas, permitiu a obtenção de atividade pectinolítica semelhante às dos Ensaios T3 e T4, porém este valor foi atingido apenas em cerca de $153 \mathrm{~h}$, aproximadamente $38 \mathrm{~h}$ mais tarde que em T3 e $81 \mathrm{~h}$ mais tarde que em T4, reduzindo o valor de produtividade volumétrica em T2 (Tabela 1).

Assim como Malvessi \& Silveira (2004), Fontana et al. (2009) e Fontana \& Silveira (2012) já demonstraram que altas produções de pectinases são observadas em meios com valor $\mathrm{pH}$ em torno de 3,0, que é desfavorável para o crescimento fúngico, sugerindo que a produção destas enzimas se dá preferencialmente em condições de estresse do microrganismo.

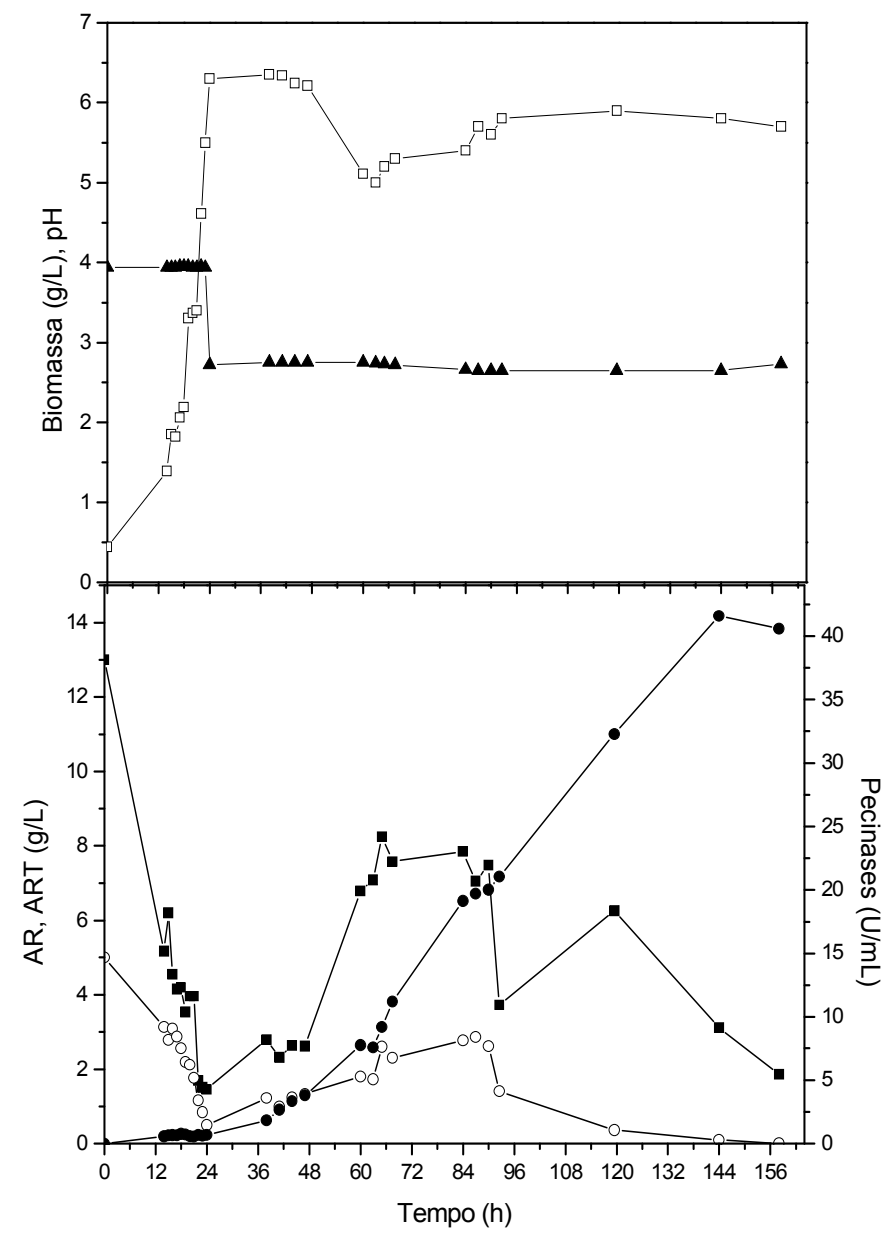

Figura 3 - Variação da atividade de pectinases, do pH e das concentrações de biomassa, açúcares redutores e açúcares redutores totais em cultivo de Aspergillus oryzae, em biorreator de bancada, no Ensaio T5 - pH ajustado e mantido em 4,0 até 24 horas de processo e queda forçada para 2,7: ( $\square$ ) biomassa, $(\mathbf{\Delta}) \mathrm{pH},(\circ) \mathrm{AR},(\boldsymbol{\bullet}) \mathrm{ART},(\bullet)$ pectinases. 
O Ensaio T5, conduzido em condições de $\mathrm{pH}$, que divide o cultivo em dois momentos crescimento celular e produção de pectinases -, foi o que resultou nas mais altas atividades enzimáticas e nos maiores valores de $\mathrm{Y}_{\mathrm{P} / \mathrm{X}}, \mathrm{Y}_{\mathrm{X} / \mathrm{S}}$ e $\mathrm{Y}_{\mathrm{P} / \mathrm{S}}$ (Tabela 1). Aparentemente, as condições facilitadas de transferência de oxigênio e mistura, aliadas ao $\mathrm{pH}$ ideal para o desenvolvimento microbiano, além de favorecerem o acúmulo de biomassa, mantiveram as células viáveis por mais tempo, tornando-as aptas à produção de pectinases quando forçou-se a queda do pH para 2,7. Os resultados deste ensaio são ilustrados na Figura 3.

Verificou-se queda na concentração de biomassa após 48h de cultivo, mantendo-se, no entanto, no mesmo patamar até $160 \mathrm{~h}$. Os perfis cinéticos de AR e ART indicam que as pectinases formadas promoveram a hidrólise da pectina do meio a compostos que foram consumidos pelo fungo, mesmo em fase estacionária. Esta afirmação está baseada no fato de o método utilizado para determinação de ART não contabilizar a pectina presente no meio e nos valores de concentração de ácido galacturônico determinados em alguns tempos de cultivo (dados não mostrados). Este composto é o principal monômero da cadeia de pectina e sua presença no meio está diretamente associada à atividade hidrolítica das pectinases.

\section{CONCLUSÕES}

Os resultados confirmam que o $\mathrm{pH}$ afeta decisivamente o cultivo de $A$. oryzae e a sua capacidade de produção de pectinases. A análise dos resultados permite concluir que em cultivo no qual o $\mathrm{pH}$ foi mantido constante em 4,0 até $24 \mathrm{~h}$ e, em seguida, reduzido para 2,7 pela adição de $\mathrm{HCl}$, foram obtidos maiores valores de concentração celular e de atividade enzimática.

\section{AGRADECIMENTOS}

Ao CNPq, à CAPES, à FAPERGS e à UCS pelo apoio na realização deste trabalho.

\section{REFEREÊNCIAS BIBLIOGRÁFICAS}

BITTMAN, R. Analysis of reducing sugars in breakfast cereal and other foods. J. Chem. Education. v. 51, p. 49, 1974.

BUSTO, M.D.; GARCÍA-TRAMONTÍN, K.E.; ORTEGA, N.; PEREZ-MATEOS, M. Preparation and properties of an immobilized pectinlyase for the tratment of fruit juices. Bioresour. Technol. v. 97, p. 1477-1483, 2006.

FAWOLE, O.B.; ODUNFA, S.A. Some factors affecting production of pectic enzymes by Aspergillus niger. Int. Biodeter. Biodegr. v. 52, p. 223-227, 2003.

FONTANA, R.C.; POLIDORO, T.A.; SILVEIRA, M.M. Comparision of stirred tank and airlift bioreactors in the production of polygalacturonases by Aspergillus oryzae. Bioresour. Technol. v. 100, p. $4493-4498,2009$.

FONTANA, R.C.; SILVEIRA, M.M. Influence of pectin, glucose, and pH on the production of endoand exo-polygalacturonase by Aspergillus oryzae in liquid medium. Braz. J. Chem. Eng. v. 29, p. 683690, 2012. 
GUMMADI, S.N.; PANDA, T. Purification and biochemical properties of microbial pectinases: a review. Process Biochem. v. 38, p. 987-996, 2003.

HOONDAL, G.S.; TEWARI, R.P.; DAHIYA, N. Microbial alkaline pectinases and their industrial applications: a review. Appl. Microbiol. Biot. v. 59, p. 409-418, 2002.

KASHYAP, D.R.; VOHRA, P.K.; CHOPRA, S.; TEWARI, R. Applications of pectinases in the commercial sector: a review. Bioresour. Technol. v. 77, p. 215-227, 2001.

MALVESSI, E. Estudo de produção de poligalacturonases por Aspergillus oryzae em processo submerso. Dissertação de mestrado. Instituto de Biotecnologia, Universidade de Caxias do Sul, 2000.

MALVESSI, E.; SILVEIRA, M.M. Influence of medium composition and $\mathrm{pH}$ on the production of polygalacturonases by Aspergillus oryzae. Braz. Arch. Biol Technol.v. 47, p. 693-702, 2004.

MENEGHEL, L. Avaliação da produção de pectinases por Aspergillus oryzae IPT-301 em processo submerso. Dissertação de mestrado. Instituto de Biotecnologia, Universidade de Caxias do Sul, 2013.

OLIVIER, M.N.; CERUTTI, E.C.; TOMIM, G.C.; FREITAS, M.B.; ROTILI, M.C.C.; GREGÓRIO, N.P. Aplicação da enzima pectinase na vinificação. Arq. Ciência Saúde Unipar. v. 12, p. 133-138, 2008.

PATIL, S.R.; DAYANAND, A. Production of pectinase from deseeded sunflower head by Aspergillus niger in submerged and solid-state conditions. Bioresour. Technol. v. 97, p. 2054-2058, 2006.

REID, I.; RICARD, M. Pectinase in paper making, solving retention problems in mechanical pulps bleached with hydrogen peroxide. Enzyme Microb. Technol. v. 12, p. 115-123, 2000.

SANDRI, I.G.; FONTANA, R.C.; BARFKNECHT, D.M.; SILVEIRA, M.M. Clarification of fruit juices by fungal pectinases. LWT - Food Sci. Technol. v. 44, p. 2217-2222, 2011.

SANDRI, I.G.; LORENZONI, C.M.T.; FONTANA, R.C.; SILVEIRA, M.M. Use of pectinases produced by a new strain of Aspergillus niger for the enzymatic treatment of apple and blueberry juice. LWT - Food Sci. Technol. v. 51, p. 469-475, 2013.

UEDA, S.; FUJIO, Y.; LIM, J.Y. Production and some properties of pectic enzymes from Aspergillus oryzae A3. J. Appl. Biochem. v. 4, p. 524-532, 1982. 